\title{
An Empirical Proof for the High Accuracy of ABC
}

\author{
Yuzhuo Cai \\ School of Accounting, Hangzhou \\ Dianzi University \\ Hangzhou Dianzi University \\ Hangzhou, China
}

\author{
Meiping Lin \\ School of Accounting, Hangzhou \\ Dianzi University \\ Hangzhou Dianzi University \\ Hangzhou, China
}

\author{
Pingxin Wang \\ School of Accounting, Hangzhou \\ Dianzi University \\ Hangzhou Dianzi University \\ Hangzhou, China
}

\begin{abstract}
Accurate cost information is the basis of management decision-making. Researches on the accuracy of $A B C$ have to remain at logical analysis limited to the difficulties in the actual data acquisition and the lack of measurement methods. On the premise of available cost data of HZ company, this paper suggests a regression model which can test the accuracy of costing methods, and presents the testing procedures and methods. Then, this paper conducts a comparison between the traditional costing and ABC by regression analysis, and comes to the conclusion that ABC is superior in accuracy.
\end{abstract}

Keywords-Accuracy; Regression analysis; Test model; Empirical evidence.

\section{INTRODUCTION}

ABC was first introduced by Professor Xuying Yu (1994) to China, and Chinese scholars never stoped studying it since then. In the late 1990s, the scholars began to shift their attention from theory study to localized application study on ABC in China (Pingxin Wang, 1999). The application of ABC in China has become gradually mature and extended after entering the 21st century (Fei Pan, 2008; Zengbiao Yu, 2005). While, there are still some scholars who question the necessity of $A B C$ by saying that $A B C$ is still in a chaotic beginning stage (Jiliang Yang, 2005). Comparative study between ABC and the traditional costing has also been made some progress (Junmin Yin et al, 2005).

What should be pointed out here is, the starting points of most domestic literatures are like which management techniques "should be used" or what problem "should be" payed attention to in enterprises, but very few literature presents effectiveness of management techniques in terms of empirical evidence (Fei Pan, 2006). Because cost data is a core trade secret in a company, which can not be revealed, it is difficult to prove that $\mathrm{ABC}$ is more accurate than the traditional costing method by using actual cost data in the academia. This situation is the same all over the world, so research results in this area are uncommon even in developed countries. This study can not be further forward due to the lack of the actual cost data, and this has become the bottleneck of it

\section{GENERAL ANALYSIS}

The cost information has always been the focus of attention

This paper is the follow-up research achievement of the project " study of Timely Activity-Based Costing” (70172010) supported by the National Natural Science Foundation of China. It's also supported by Zhejiang Provincial “Accounting Engineering Experimental Teaching Demonstration Center” [Zhejiang Educational Office of Higher Education (2010) No.183] and the project "Study of Activity-Based Costing System Optimization" (Y201224759) of Zhejiang Provincial Scientific Research program of the Education Department of China. in enterprises. Yanren Xiong et al's survey (2008) found that managers in Chinese enterprises consider the cost information more in budgeting, product pricing and performance evaluation than in other areas. Budgeting, cost control, and performance evaluation affect enterprise efficiency indirectly through pre-product, in-product and ex-product cost control. The product pricing decision impacts directly on sales and profits of an enterprise, so it's a strategic decision-making issue. All these, budgeting, cost control, performance evaluation and product pricing, are inseparable from the accurate product cost information. So the product cost information is also a strategic information. It is a matter of course for enterprises to keep the product cost information secret. But an important question is: cost information of one certain product differs due to the different costing methods. Especially in the rapid development of technology today, user demand is in gradually diversification, and costs unrelated to output and working hours (such as inspection costs, maintenance costs, waste treatment costs, etc.) have increased significantly. Production diversification of processes, alternate production, difference in batchsize and other factors bring great difficulties in accurate cost allocation. Therefore, ABC rised up independently of the traditional costing.

$\mathrm{ABC}$ measures the direct costs in the same way as the traditional costing. The difference between them lies in the allocation of indirect manufacturing costs. All the indirect manufacturing costs are assigned to products through a unified allocation base (generally labor-hour) under traditional costing. In contrast, the $\mathrm{ABC}$ theory believes that most of the indirect manufacturing costs are associated with activities: the activities consume resources directly and products consume resources indirectly by consuming the activities. First, ABC assigns various resources to the activities through resource driver. Then the activity cost rates are calculated according to the number of activity driver. Finally, complete the calculation of product costs based on the activity cost rate and the amount of activities consumed by each product

Activity-based costing differs much from the traditional costing which based on working hours. It is bound to wide variations of cost information under the two different costing methods. This will definitely affect the cost control, performance evaluation and decision-making. Which method of the two is more accurate than the other? This can only be determined by empirical evidence in a mathematical way. 


\section{REGRESSION ANALYSIS}

The premise of regression analysis is that cost data of a typical company (both traditional costing data and ABC data) is available. Regression analysis procedures are as follows: First, we need to design a regression model and get the company's historical cost data and other related data. Then, the company's traditional costing data and $\mathrm{ABC}$ data will be substituted into the model respectively. Last, we analyze the statistical parameters obtained in last step and draw a conclusion.

\section{A. Regression Analysis Procedures of Traditional Costing Test}

All the indirect manufacturing costs are assigned to products through one allocation base under traditional costing. This allocation method is based on the assumption that all indirect manufacturing costs have linear relation with the unified allocation base, so the procedures are as follows:

\section{1) Model Building}

Statistically, people test linear relation using a simple linear regression model. So, the paper builds a simple linear regression equation whose dependent variable is the sum of indirect manufacturing costs (C) and independent variable is the unified allocation base (Q) as the traditional costing test model:

$$
\mathrm{C}=\alpha_{0}+\alpha_{1} \mathrm{Q}+\varepsilon
$$

Where $\varepsilon^{\sim N}\left(0, \sigma^{2}\right), \quad \alpha_{0}, \alpha_{1}$ and $\sigma$ are unknown parameters.

\section{2) Data Collection}

Companies successfully implement ABC provide only the $\mathrm{ABC}$ data, so it's necessary to convert the $\mathrm{ABC}$ data to traditional costing data. The dependent variable $(C)$ is the sum of indirect manufacturing costs. And there is always a resource center of labor costs whose resource driver is labor-hour (Q) in ABC system. So, it's not difficult to collect the data the model needs from historical ABC data of a company.

\section{3) Data Substitution.}

We need to substitute the data collected into the regression model. $\alpha_{0}$ and $\alpha_{1}$ will be easily fixed by using regression method.

\section{4) Statistic Analysis}

According to the purpose of testing linear relation, this paper focuses on three statistical parameters: R-squared, Tstatistic and F-statistic. R-squared measures the accuracy of the model; the T-statistic and F-statistic are for model evaluation. The more R-squared is close to 1 , the higher the degree of model fitting is, and the higher correlation between $\mathrm{Q}$ and $\mathrm{C}$ there is. This means that it's accurate to assign costs through $\mathrm{C}$ (labor-hour). R-squared is the square of the correlation coefficient in simple linear regression, so we can define a lower limit by checking the threshold of correlation coefficient. If R-squared is lower than the lower limit, then there is no significant correlation between independent and the dependent variables. T-statistic is used for significance test of $\alpha_{0}$ and $\alpha_{1}$ (T-test). F-statistic is for significance test of the regression equation (F-test). In the analysis of simple linear regression, the F-test will draw the same conclusion with the T-test of $\alpha_{1}$, so we focus on the T-statistic of $\alpha_{1}$. If $\alpha_{0}$ and $\alpha_{1}$ pass the T-test, we can say the model is statistically significant.

\section{B. Regression Analysis Procedures of ABC Test}

Cost absorption under $\mathrm{ABC}$ is divided into two steps: activities consume the resources and products consume the activities. Correspondingly, what should be considered is not only the correlation of the resources and resource drivers, but the correlation of activities and activity drivers. The resource driver data are commonly acquired by means of measurement, so that the resources allocated to activity center are just the amount actually consumed here. Because of this, there is no need to test the correlation of resources and resource drivers. For the activity driver, one activity center usually contains several activities, and the cost absorption can not be that accurate after considering importance principle. In practice, a suboptimal, unrepresentative driver is usually selected to accord with cost-benefit rule. Therefore, the test of correlation between activity costs and activity drivers is the highlight in $\mathrm{ABC}$ test.

The testing model is also a simple linear regression equation. As to a certain activity center $\mathrm{j}$, dependent variable in the equation is the total activity cost $\left(C_{j}\right)$ and independent variable is the number of the activity driver $\left(\mathrm{q}_{\mathrm{j}}\right)$ :

$$
\mathrm{C}_{\mathrm{j}}=\beta_{0}+\beta_{1} \mathrm{q}+\xi
$$

Where $\xi \sim \mathrm{N}\left(0, \delta^{2}\right), \beta_{0}, \beta_{1}$ and $\delta$ are unknown parameters.

The specific procedures are similar to those in traditional costing test. If the correlation of activity cost and activity driver is statistically significant in each activity center, it can be deduced that ABC system is admirable in accuracy.

\section{CASE STUDY}

This article takes the fermentation workshop of $\mathrm{HZ}$ company as an example, whose available ABC data is for a 41month period (January 2009 to May 2012). A comparative analysis of costing accuracy will be progressed using the above analysis model.

There are four main products named A, B, C and D in the fermentation workshop. Resources consumed in the workshop are as follows: raw material, labor, power (water, electricity, compressed air, refrigeration, steam), maintenance fees, inspection fees, management fees, depreciation expenses of equipment and plant, etc. Cost of raw materials is not included in the comparisons because there is no difference between the two costing methods in assignment of it. And the depreciation expenses are excluded as fixed costs, too.

\section{A. Accuracy Test of the Traditional Costing}

Traditional costing method was used in HZ company before the implementation of the ABC method, using laborhour as the allocation criteria of indirect costs. In the $A B C$ system, labor-hour is the resource diver of the labor resource center, so the labor-hour data are available as Q in the Eq. 1. 
And the sum of costs of resources except raw material costs and depreciation expenses is C. Table 1 presents the results of data substitution.

TABLE 1 RESULT OF CORRELATION TEST IN TRADITIONAL COSTING METHOD

\begin{tabular}{|c|c|c|c|}
\hline Dependent variable & Variable & Coefficient & R-squared \\
\hline \multirow{2}{*}{ C } & $\alpha_{0}$ & $\begin{array}{c}3955669 \\
\left(26.60745^{* * *}\right)\end{array}$ & \multirow{2}{*}{0.126238} \\
\cline { 2 - 3 } & $\alpha_{1}$ & $\begin{array}{c}2540.521 \\
\left(2.150176^{* *}\right)\end{array}$ & \\
\hline \multicolumn{2}{|c|}{ Note: T-statistics are reported in brackets. ***, **, and * represent coefficients statistically }
\end{tabular}
significant at the $1 \%, 5 \%$ and $10 \%$ levels, respectively. The same below.

Although the regression coefficients pass T-test, what means the model is statistically significant, R-squared statistic is only 0.126238 due to the very low correlation between the dependent and independent variables. To reduce the false acceptance rate, we take the significance level of 0.01 . When there are $39(41-2)$ degrees of freedom, the critical value of the correlation coefficient, $\mathrm{R}_{0.01}$ is 0.398 . So the lower limit of Rsquared may be determined to be 0.158404 , even higher than the R-squared statistic obtained in the test. It can be concluded that: the independent and dependent variables in the model are not significantly correlated. That is to say there is no significant relationship between labor-hour and indirect manufacturing costs. The accuracy of the traditional costing method is not optimistic.

\section{B. Accuracy Test of $A B C$}

The production processes of the four products in the fermentation workshop are very complex, resulting in numerous secondary activities. The production processes can be simplified into the 4 activity procedures after analysis: fermentation, air drying, extraction and purification.

Specifically, only A and B require air drying, and D does not need to be purified. Extraction and purification processes of $\mathrm{C}$ located in different places from other products, so they need to be separated. Informations of activity centers and activity drivers in the workshop are shown in the following table:

TABLE 2 INFORMATION OF ACTIVITY CENTER AND ACTIVITY DRIVER

\begin{tabular}{|c|c|c|}
\hline Activity center & Product(s) involved & Activity driver \\
\hline Fermentation & A、B、C、D & Fermenting hour \\
\hline Air drying & A, B & machine-hour of dryers \\
\hline Extraction 1 & A、B、D & Extracting hour \\
\hline Extraction 2 & C & $1^{*}$ \\
\hline Purification 1 & A、B & Purifying hour \\
\hline Purification 2 & C & 1 \\
\hline \multicolumn{2}{|c|}{ Note: The selection of activity driver will not affect the cost allocation when there is only one } \\
product involved in a activity center, and the activity driver is set "1".
\end{tabular}

There is no need to test Extraction 2 and Purification 2 because their activity drivers are both "1". But extracting hour and purifying hour are noted in the two activity center (easy to get), so it is no exertion to test them as a corroborator. The regression results are shown in the following table:
TABLE 3 REGRESSION RESULTS

\begin{tabular}{|c|c|c|c|}
\hline Dependent variable & Variable & Coefficient & R-squared \\
\hline \multirow{2}{*}{$\mathrm{C}_{\text {Fermentation }}$} & $\beta_{0 \text { Fermentation }}$ & $\begin{array}{c}737750.7 \\
\left(2.684461^{* *}\right) \\
\end{array}$ & \multirow{2}{*}{0.513511} \\
\hline & $\beta_{1 \text { Fermentation }}$ & $\begin{array}{c}127.4228 \\
(5.13699 * * *)\end{array}$ & \\
\hline \multirow{2}{*}{$\mathrm{C}_{\text {Air drying }}$} & $\beta_{0 \text { Air drying }}$ & $\begin{array}{c}46615.05 \\
(1.066096)\end{array}$ & \multirow{2}{*}{0.64177} \\
\hline & $\beta_{1 \text { Air drying }}$ & $\begin{array}{r}2553.518 \\
\left(6.69235^{* * *}\right) \\
\end{array}$ & \\
\hline \multirow{2}{*}{$\mathrm{C}_{\text {Extraction } 1}$} & $\beta_{0 \text { Extraction } 1}$ & $\begin{array}{c}23451.03 \\
\left(1.787843^{*}\right)\end{array}$ & \multirow{2}{*}{0.698337} \\
\hline & $\beta_{1 \text { Extraction } 1}$ & $\begin{array}{c}1385.109 \\
\left(6.632054^{* * *}\right)\end{array}$ & \\
\hline \multirow{2}{*}{$\mathrm{C}_{\text {Extraction } 2}$} & $\beta_{0 \text { Extraction } 2}$ & $\begin{array}{c}111445 \\
\left(4.61625^{* * *}\right)\end{array}$ & \multirow{2}{*}{0.646182} \\
\hline & $\beta_{1 \text { Extraction } 2}$ & $\begin{array}{c}1120.846 \\
(6.757048 * * *) \\
\end{array}$ & \\
\hline \multirow{2}{*}{$\mathrm{C}_{\text {Purification } 1}$} & $\beta_{0}$ Purification 1 & $\begin{array}{l}-3865.759 \\
(-0.95165) \\
\end{array}$ & \multirow{2}{*}{0.811301} \\
\hline & $\beta_{1}$ Purification 1 & $\begin{array}{c}1081.22 \\
\left(10.36757^{* * *}\right)\end{array}$ & \\
\hline \multirow{2}{*}{$\mathrm{C}_{\text {Purification } 2}$} & $\beta_{0}$ Purification 2 & $\begin{array}{c}831.485 \\
(0.769625) \\
\end{array}$ & \multirow{2}{*}{0.650464} \\
\hline & $\beta_{1}$ Purification 2 & $\begin{array}{c}136.0714 \\
\left(5.946235^{* * *}\right)\end{array}$ & \\
\hline
\end{tabular}

The table above shows that, the minimum R-squared statistic 0.513511 appears in the regression result of fermentation activity center, but it's still much higher than the lower limit of 0.158404 . All regression coefficients $\left(\beta_{1} \mathrm{~s}\right)$ before activity drivers pass the T-test and are statistically significant at level of $1 \%$. The results show a high correlation between activity cost and activity driver in every activity center. The constant terms $\left(\beta_{0}\right)$ of regression equations built in fermentation, extraction 1 and 2 pass T-test, while $\beta 0$ s in the results of air drying, purification 1 and 2 fail to pass it. This phenomenon does not negate the correlation of dependent and independent variables, but it means we can not reject the null hypothesis of $\beta_{0}=0$. In realistic situations, long-term maintenance of low temperature and other working conditions exist in the fermentation and extraction activities. There is still resource consumption when the fermentation and extraction stop, For this reason, relatively fixed costs unrelated to activity driver exist in all probability. On the contrary, processing of air drying and purification require no environmental condition, so there's hardly any relatively fixed cost in air drying and purification. Therefore, let's consider changing the linear regression model of air drying and purification by forcing $\beta_{0}=$ 0 :

$$
C_{j}=\beta_{1}^{\prime} q+\xi^{\prime}
$$

Where $\xi^{\prime} \sim \mathrm{N}\left(0, \delta^{\prime 2}\right), \beta_{1}{ }^{\prime}$ and $\delta^{\prime}$ are unknown parameters. 
And then we substitute the data of air drying and purification activity center into Eq. 3. Results are listed in table 4, in which each R-squared is far above the lower level and each T-statistic is statistically significant at level of $1 \%$. This indicates that the three activity centers suit the model without constant.

TABLE 4 REGRESSION RESULTS AFTER FORCING $\beta_{0}=0$

\begin{tabular}{|c|c|c|c|}
\hline Dependent variable & Variable & Coefficient & R-squared \\
\hline$C_{\text {Air drying }}$ & $\beta_{1}^{\prime}$ Air drying & $\begin{array}{c}2939.685 \\
\left(24.45074^{* * *}\right)\end{array}$ & 0.625484 \\
\hline$C_{\text {Purification 1 }}$ & $\beta_{1}^{\prime}$ Purification 1 & $\begin{array}{c}993.2776 \\
\left(20.58678^{* * *}\right)\end{array}$ & 0.804466 \\
\hline$C_{\text {Purification 2 }}$ & $\beta_{1}^{\prime}$ Purification 2 & $\begin{array}{c}150.9876 \\
\left(12.5382^{* * *}\right)\end{array}$ & 0.639567 \\
\hline
\end{tabular}

The analysis above reveals the statistically significant correlation of activity cost and driver in every activity center of $\mathrm{X}$ workshop. This means the assignment of activity cost is relatively accurate in every activity center of $\mathrm{X}$ workshop.

\section{CONCLUSION}

This paper generally analyzes the different allocation method of traditional and activity-based costing in the beginning, and then set up linear regression models to test the accuracy of traditional costing and ABC. At last, regression analysises of traditional costing data and $\mathrm{ABC}$ data are completed respectively based on the linear regression models and historical cost data of HZ company in case study. The analysis results show that there is no significant correlation between cost and its only allocation base in traditional costing method, indicating the poor quality of the traditional cost information; while activity cost shows significant correlation with activity driver in every activity center, indicating the allocation of activity cost is relatively accurate in every center.

Holism holds that the whole is greater than the sum of its parts, so the overall accuracy of ABC system can be deduced here. In conclusion, the high accuracy of $A B C$ is confirmed through empirical tests.

\section{REFERENCES}

[1] Pingxin Wang, Xinmin Han, Qinglu Le. Activity-based Costing, Management and Their Realistic Application in China. Accounting Research. 1999(8): 37 40.

[2] Fei Pan, Yue Wang, Qian Li, Wenwen Ren, Gang Li. Developments and Innovations of Chinese Management Accouting in the Past Thirty Years of Reform and Opening-up: Cost Management Practice and Revelation of Xuji Electric and Baoshan Iron \& Steel. Accounting Research.2008. (9):10-16.

[3] Jiliang Yang. A Survey on the Aboad Implementation of ABC. Accounting Research.2005. (7).

[4] Fei Pan, Donghua Wen. Status and Future Direction of Empirical Management Accounting Research in China: from the Value Management Perspective. Accounting Research. 2006.(2).

[5] Yanren Xiong, Wenbing Su. Present Condition and Prospect of Management Accounting Practice: A Survey of the Application of Advanced Management Accounting Tools in China. Accounting Research. 2008. 11.

[6] Cooper, R. and Kaplan, R.S., "Measure Costs Right: Make the Right Decisions", Harvard Business Review,Vol. 66 No. 5, SeptemberOctober 1988, pp. 96-103. 